\title{
Programme proposé basé sur l'approche pragmatique à la lueur de la communication interculturelle pour développer les compétences de la traduction chez les futurs enseignants du Français à la Faculté de pédagogie
}

\section{Préparée Par}

\section{Mahmoud Ezz El-Arab El- Sayed*}

\section{Introduction :}

La traduction (le fait de transposer un texte d'une langue à une autre) a un rôle majeur dans la marche des choses, la vie quotidienne, l'information, les échanges, les activités culturelles et dans les activités économiques, etc. Ce rôle qui tend à s'accroître avec la multiplication des échanges dans lesquelles les partenaires sont de langue différente est une des conséquences de la mondialisation. Il est tout aussi juste de dire que la traduction est également la langue de la mondialisation.

Les échanges interculturels existent depuis longtemps, mais, avec les technologies qui ont accentué le rythme des rencontres avec l'autre, les enjeux interculturels sont devenus majeurs aujourd'hui devant la diversité et la multiplicité des contacts culturels. Dans cette société métissée, la conscience des différences font désormais partie de notre identité. (Chaplier ,2012 : 147)

\footnotetext{
*Maitre de Conférence - Département de Curricula Faculté de Pédagogie Université de Damiette
} 
La traduction soutient les échanges culturels à double sens : entre individus, elle facilite la compréhension mutuelle, les rencontres et les transactions entre des personnes de différentes cultures. Elle permet à un individu d'accéder aux cultures étrangères et aux cultures anciennes, et permet aussi de diffuser une culture ou un point de vue vers le reste du monde ; d'ailleurs, certains états, autorités régionales ou organisations mènent des politiques en ce sens, par exemple pour consolider une langue, avec comme objectif de renforcer l'identité d'un peuple ou d'un groupe. ( Commission européenne - Direction générale de la traduction, $2010: 4$ )

Les différentes informations qui constituent l'environnement cognitif total du traducteur relèvent de plusieurs disciplines scientifiques spécialisées. Les connaissances interdisciplinaires $\mathrm{du}$ traducteur lui permettraient de résoudre les problèmes de traduction en lui dictant le choix des stratégies traductionnelles. Cette interdisciplinarité jouerait également un rôle essentiel dans la construction du contexte et imposerait au traducteur un type nouveau de savoir en lui fournissant les différentes informations contextuelles. Ces informations forment un tout cohérent qui concourt harmonieusement à la réexpression du texte source en langue cible. (Musampa, 2011 : 30)

En d'autres termes, la nature du processus de la traduction comporte plusieurs interdisciplinarité : la nature complexe du processus de traduction, la nature contextuelle et la nature interprétative de l'opération de traduction.

D'ici, Gile voit que La connaissance des signes de la langue est indispensable pour comprendre un énoncé, mais elle n'est pas suffisante, car il n'est plus possible de les interpréter si on ne sait pas quelque chose de la réalité extralinguistique qu'ils désignent. (Gile, 2005 : 108)

D'autre terme, , le traducteur doit posséder un " bagage cognitif qui englobe la connaissance du monde, la saisie du contexte et la compréhension du vouloir dire de l'auteur. 
D'ailleurs, l'interculturalité ou l'interdisciplinarité n'est pas représentée, dans le processus de la traduction, comme simple corrélation soit au cours de l'interprétation du texte source ou soit au cours de la recherche d'un équivalent en langue cible. L'interculturalité est un fait qui impose, en plus un nouveau style de savoir, un nouveau mode de discours intellectuel basé, entre autres, sur la redécouverte, la reconceptualisation, etc. (Crevier, 2002 : 108)

C'est pour cela, la traduction est un fait complexe; elle se déroule de manière inférentielle et s'inscrit toujours dans un schéma intentionnel. Dans sa complexité, elle s'inscrit toujours dans un contexte, au point que cette expression est nécessairement vraie : " pas de traduction en dehors du texte ». Sinon, l'on ne fait que du transcodage pur et simple. La traduction porte ainsi sur les énoncés du message. Et le contexte par rapport auquel l'énoncé est interprété et constitué d'informations tirées de l'environnement cognitif, (Abplanalp, 2001 : 68).

Donc, le traducteur interprète le message au moyen de différentes informations (connaissances). Ces connaissances sont utilisées de manière harmonieuse pour comprendre le message en langue source et pour le ré - énoncer en langue cible. L' Interculturalité impose au traducteur un nouveau type de savoir et joue un rôle essentiel dans la construction du contexte.

Parallèlement, Guidère supportent le sens en affirmant que la traduction est devenue une activité de médiation interculturelle. L'enseignement de la traduction a subi une évolution parallèle. L'approche contrastive de la traduction, qui considère que celleci consiste «à changer de formes linguistiques en préservant le sens textuel » a cédé le pas à une approche fonctionnelle, qui vise à « produire un texte susceptible de fonctionner dans une culture différente et auprès de récepteurs étrangers » (Guidère, 2010 : 113) 
Selon Tatilon, traduire, c'est « reformuler un texte dans une autre langue, en prenant soin de conserver son contenu », ou encore «traduire est une opération qui a pour but de fabriquer, sur le modèle d'un texte de départ, un texte d'arrivée dont l'information soit - dans chacun de ses aspects : référentiel, pragmatique, dialectal, stylistique - aussi proche que possible de celle contenue dans le texte de départ ». (Tatilon, $1986: 7$ )

A cet égard, on peut dire que la traduction est une opération de communication interculturelle, la traduction ne peut plus être enseignée seulement à travers des exercices linguistiques ,mais doit intégrer une réflexion sur les contextes et les fins de la communication en langue cible, De même, le traducteur doit développer au cours de son apprentissage une compétence culturelle lui permettant de gérer la complexité du processus de traduction .

C'est pourquoi, La traduction n' est pas une tâche facile en raison des différences entre les langues et les cultures. Par conséquent, les différents traducteurs et linguistes, suggèrent l'application de la théorie linguistique sur la discipline traduction. Cette application linguistique sur la pratique de la traduction est appliquée sous la forme de différentes approches. L'une de ces approches sur la traduction est l' approche pragmatique.( Triki, $2013: 39$ )

La Pragmatique offre une manière plus précise de déterminer ces notions, offrant ainsi une méthodologie mieux spécifiée de traduction. La traduction a bénéficié de ce tour pragmatique, mais le traducteur doit être très versé dans cette approche pour améliorer sa langue et sa méthodologie et le résultat final. (kitis: 2009: 82)

De plus, les étudiants de traduction et les traducteurs en général font des erreurs pragmatiques dues à plusieurs raisons, comme le manque de la connaissance pragmatique, et l'importance de la pragmatique dans la tâche de la traduction. (Triki , 2013 : 40) 
Levinson définit la pragmatique comme relation entre la structure et l'extra contexte linguistique. "II se concentre sur comment les expressions linguistiques sont codées par leur contexte. (Levinson, 1983: 8)

Pour Yule, la pragmatique s'agit d'étudier le sens communiquée par un parleur (ou écrivain) et interprété par un auditeur (ou lecteur). La pragmatique est aussi l'étude d' utilisation de la langue et les utilisateurs de la langue. Il est la relation qui existe entre le phrase ou l'énoncé et l'utilisateur de cet énoncé. Il concerne la relation entre le sens des phrases et l'intention de parleurs. (Yule, 1983: 8)

La traduction est cruciale pour la compréhension interculturelle car elle révèle les idéologies, les politiques et les expériences sociales. De même, elle permet de mettre en évidence les nuances de sens en construisant des ponts entre les esprits et les langues.

Par rapport, l'adaptation translationnelle possède son propre attrait parce que les modèles adaptatifs et les textes pragmatiques explicitent la nécessité de l'utilisation des transformations précises qui se traduit par le lien de la théorie communicative, pragmatique linguistique et la théorie de traduction . ces modèles décrivent les changements transformationnels tout transcodage d'une langue à l'autre, $d^{\prime}$ une culture à une autre.

L'adaptation comme un des types de la médiation linguistiques est considérée par la majorité des chercheurs comme le degré extrême de transformations admissibles en traduction. Le but principal de stratégies d'adaptation réside à la fois le transfert du potentiel pragmatique du discours / texte et de l'orientation à la linguistique et les stéréotypes culturels pendant la traduction. (Demetska, 2011 : 15)

Autrement, l'adaptation est un système de développement social, liens culturels, pragmatiques et linguistiques entre texte intégral et cible. l'adaptation est sur le haut de la hiérarchie. A 
ce niveau, un traducteur prend une décision d'adapter un texte intégral ou une partie particulière de celui-ci. Un traducteur peut être influencé soit par des facteurs intrinsèques (Par exemple, des difficultés de traduction du texte source) ou par des facteurs extrinsèques (par exemple, une brève traduction, un nouvel environnement linguistique, les attentes du public cible, etc. ( Volkova et Zubenina 2011: 91)

De même, La traduction pourrait donc être considéré comme une technique métacognitive, et métalinguistique et métaculturelle à être utilisé dans l'enseignement de FLE .la traduction vise à produire des compétences méta linguistiques et culturelles qui aideront l'élève dans la production et l'utilisation d'une langue cible.

Par conséquent, La traduction est un clé donnant un accès à une culture étrangère dans ce qu'elle a de plus intime ; la langue et les valeurs qu'elle exprime. Elle prépare au dialogue en exposant une culture et sa représentation de l'univers dans lequel vit l'Étranger. Elle prédispose à la diversification du dialogue en représentant les différences culturelles autant que linguistiques. Enfin, en contribuant à établir l'égalité entre les langues et les cultures, elle est un vecteur de médiation inter linguistique et interculturelle.( GUTU, 2002 : 11)

Ainsi , la traduction est un moyen efficace pour la communication entre les cultures. la communication inter culturelle indique un point de contact entre les différentes cultures où deux cultures qui se rencontrent les uns les autres. La traduction implique transférer des langues et des cultures associées à des récepteurs «étrangers». Ces récepteurs ont à leur disposition des systèmes établis de représentation avec les normes et les conventions pour la production de significations vis-à-vis des personnes, des objets et des événements. Ces systèmes donnent finalement un discours ou un texte à travers lesquelles l'identité et la différence sont marquées et au sein de laquelle la traduction est effectuée. (SAWANT, 2010 : 5) 
A l'issue de ce qui suit, on peut dire que la traduction est un processus de communication interculturelle visant à produire des messages appropriés à des situations spécifiques et à des contextes professionnels .dont l'objectif est de réduire les obstacles culturels qui empêche la communication de se faire de façon efficace.

Parmi une variété d'approches linguistiques qui ont été utilisées dans l'analyse de la traduction, la théorie de l'adaptation Pragmatique, proposé par Verschueren. L'utilisation de la langue est une prise continue des choix linguistiques avec des différents degrés de saillance à des fins d'adaptation.

La traduction, comme une sorte d'usage de la langue, ne fait pas exception. Les traducteurs, d'abord en tant que lecteurs, comprennent des textes originaux à travers leurs langues; puis en tant que les médiateurs, transférer des textes sources par leur adaptation à leurs langues cibles. L'ensemble du processus de traduction implique incessants choix d'adaptation des traducteurs sous forme de langue et du contenu, ainsi que dans les stratégies de traduction. ( Zhang, 2014 : 155)

En général, l'adaptation peut être comprise comme un ensemble d'interventions translatifs qui sont un résultat de traduire un texte généralement n'accepté pas, mais néanmoins reconnue comme un texte source. La phénomène d'adaptation est susceptible de 'embrasser diverses notions vagues telles que la réécriture, l'appropriation ou le transediting. Cependant, le but de créer un produit qui est plus indépendant du texte source. Ce produit nécessite moins d'équivalence que celle créée avec l'aide de l'adaptation. (Baker et Saldanha, 2011 : 41).

C'est pour cela, Volkova et Zubenina assurent que l'importance de l'adaptation en déclarant que «si un traducteur refuse systématiquement d'adapter, il finira par conduire à un affaiblissement d'un texte cible ». Ce point de vue offre une compréhension claire de l'adaptation comme une partie inévitable du processus de traduction qui vise à renforcer la connexion entre 
textes sources et cibles et entre source et cible le public. ( Volkova et Zubenina , 2011: 89)

Tsaturova et Kashirina interprètent la traduction interculturelle comme un processus dans laquelle le contenu du message est modifiée pour se conformer à la culture de récepteur et / ou dans lequel est introduit des informations qui ne sont pas linguistiquement impliquâtes. Cela se reflète désormais la traduction comme «un processus de la communication interculturelle et inter linguistique partant d'une analyse cohérente du texte de départ et ayant pour objectif de créer un texte secondaire susceptible de remplacer le texte source dans un nouveau milieu linguistique et culturel». (Tsaturova et Kashirina ,2008 : 75)

D'ici, on peut signaler que les apprenants pendant le processus de traduction naviguent clairement parmi différents rôles personnels, professionnels, linguistiques et culturelles. les méthodes dans lesquelles ils réfléchissent à leur identité et leur rôle multilingue qui contribuent également à leurs attitudes et leurs approches au sujet de la traduction. La traduction est plus encore que d'autres formes de communication multilingues.

\section{Position de problème:}

La mondialisation est une vraie force de changement qui est en train de restructurer notre identité culturelle. L'identité qui n'est plus basée uniquement sur notre nationalité ou notre situation géographique, mais aussi sur notre expérience de vie dans une société qui, comme beaucoup d'autres sociétés industrialisées, a incorporé de nombreuses cultures. Il est donc important pour les enseignants de langues de repenser à la nature de la culture d'un point de vue pédagogique, et de réfléchir au contexte mondial et académique dans lesquels ils préparent leurs cours de langue. 
De nombreuses recherches en linguistique et en didactique des langues comme (Zaghouani - Dhaouadi 2008, Caws 2009, Fath,2009, Kosonen 2011, Omar et Mohamed 2014 ) s'accordent, aujourd'hui, à dire qu'il existe une relation intime entre la langue et la culture ; la bonne connaissance de la langue, à la fois réceptacle et miroir des valeurs inhérentes à une société, ses symboles, ses codes, ses habitus et ses réalités sémiotiques, etc. est inséparable d'une bonne connaissance de sa culture.

La traduction favorise la spéculation et la discussion, et il contribue au développement des capacités considérées comme fondamentales pour la communication, tels que l'interprétation, la négociation, et l'expression de sens. Selon Alan Duff, "traduction développe trois qualités essentielles à tous l'apprentissage des langues; la précision, la clarté et la flexibilité. Il suscite l'apprenant à la recherche (flexibilité) pour les mots les plus appropriés (précision) de transmettre ce que l'on entend (clarté) ". (Coban, 2015: 710)

Il y a d'autres écrits comme (Gut 1991, Pettinen1998, Natunen 2003, Koivisto 2006) qui soulignent qu' il y a des interactions entre la pragmatique et la traduction, Ils soulèvent également quelques problèmes de traduction qui se produisent en raison des différences pragmatiques entre la langue source et la langue cible. on devrait maintenir le même pragmatique effet du texte source sur le texte cible. De plus, ils ajoutent que la traduction est une situation de communication dans laquelle les traducteurs interprètent et présentent des indices de communication dans les textes.

L'étude pilote a montré des résultats variés comme suit: quelques futurs enseignants de Français à la quatrième année dans la faculté de pédagogie pendant la tâche de traduction, la plupart du temps, ne donnent aucune importance aux aspects pragmatiques dans un certain texte lors de la traduction. Ils ne sont pas conscients de l'importance de la traduction pragmatique. La plupart du temps, ils ont traduit littéralement les énoncés 
originaux, quel que soit le contexte dans lequel les énoncés sont produits. Les autres ont montré une faiblesse tangible dans les compétences de la traduction. Ils ne peuvent pas performer les compétences de la traduction demandées.

De telle sorte que l'étude actuelle essaie d'élaborer un programme basé sur l'approche pragmatique à la lueur de la communication interculturelle pour développer les compétences de la traduction chez les futurs enseignants de Français à la faculté de pédagogie.

\section{Problématique de la recherche :}

A la lueur des résultats des études antérieures et de l'étude pilote ,le problème de cette recherche se manifeste dans le manque des compétences de la traduction au cadre de la communication interculturelle chez les étudiants de la quatrième année à la section de français dans la faculté de Pédagogie. Ce manque est dû à l'utilisation des stratégies d'enseignement qui ne font pas attention à l'adaptation pragmatique des futurs enseignants pendant la traduction.

L'étude actuelle essaie de vérifier l'efficacité d'un programme basé sur l'approche pragmatique à la lueur de la communication interculturelle pour développer les compétences de la traduction chez les futurs enseignants de Français à la faculté de pédagogie

Notre étude actuelle essaie de répondre à la question principale suivante :

"Quel est l'efficacité du programme proposé basé sur l'approche pragmatique à la lueur de la communication interculturelle pour développer les compétences de la traduction chez les futurs enseignants du Français à la Faculté de pédagogie ?" 
1- Quelles sont les compétences de la traduction nécessaires aux futurs enseignants du français dans la faculté de pédagogie?

2- Jusqu'à quel niveau les futurs enseignants du français à la faculté de pédagogie possèdent-ils ces compétences ?

3- Quelle est la représentation suggérée pour préparer un programme basé sur l'approche pragmatique à la lueur de la communication interculturelle pour développer les compétences de la traduction chez les futurs enseignants du Français à la faculté de pédagogie?

4- Quelle est l'efficacité du programme proposé basé sur l'approche pragmatique à la lueur de la communication interculturelle pour développer les compétences de la traduction chez les futurs enseignants de Français à la faculté de pédagogie?

\section{Objectifs de la recherche ;}

\section{La recherche actuelle a pour objectif de :}

- Développer les compétences de traduction comme moyen de communication interculturelle en français chez les étudiants de la quatrième année de la section de français à la faculté de pédagogie.

- Vérifier l'efficacité d'un programme basé sur l'approche pragmatique à la lueur de la communication interculturelle sur le développement de certaines compétences de traduction.

\section{Importance de la recherche :}

\section{Cette recherche peut contribuer à :}

- Montrer l'importance pédagogique de l'adaptation pragmatique interculturelle et sa rôle dans le développement des 


$$
\text { مجلة كلية التربية بالإسماعيلية - العدد الثامن والثلاثون - مايو r. PV }
$$

compétences langagières généralement et la traduction particulièrement.

- Rendre les futurs enseignants plus attentifs et conscients des aspects de la communication interculturelle en les pratiquant à travers la traduction.

- Dégager les différentes compétences de la traduction nécessaires aux futurs enseignants du français au cadre de la communication interculturelle.

- Elaborer un test pour évaluer les compétences de la traduction .

- Attirer l'attention des spécialistes vers la dimension socioculturelle pendant le processus de la traduction.

- Ouvrir de nouveaux horizon à d'autres études portant l'approche pragmatique interculturelle pour développer d'autres compétences langagières.

\section{Limites de la recherche:}

La présente recherche se limite à :

- Un échantillon d'étudiants de la quatrième année à la section du Français dans la faculté de pédagogie de Damiette.

- Quelques compétences de traduction nécessaires aux étudiants de la quatrième année à la section du Français dans la faculté de pédagogie.

\section{Outils et matériaux de la recherche:}

Le chercheur a élaboré les outils suivants:

- Une questionnaire ayant pour but d'identifier les compétences de la traduction nécessaires aux futurs enseignants du Français à la faculté de la pédagogie. 
- Un pré-post test pour mesurer les compétences de la traduction chez les futurs enseignants du français à la faculté de la pédagogie.

- Un programme basé sur l'approche pragmatique à la lueur de la communication interculturelle afin de développer les compétences de la traduction en FLE.

\section{Hypothèses de la recherche:}

La recherche actuelle a examiné les hypothèses suivantes :

- Il y a une différence statistiquement significative entre les moyennes des notes du groupe expérimental au pré et post-test de la traduction en faveur du post-test.

- Le programme basé sur l'approche pragmatique à la lueur de la communication interculturelle a une efficacité pour améliorer les compétences de la traduction.

\section{Plan de la recherche:}

Pour répondre aux questions précédemment citées, nous avons procédé de la manière suivante :

- Etude théorique réflexive des études antérieures et des ouvrages (arabes et étrangers) portant sur :

A) la définition de la traduction, ses compétences, ses technique et les stratégies favorables à la traduction.

B) la signification de l'approche pragmatique, la communication interculturelle, l'adaptation pragmatique, ses types, ses causes, sa relation avec la traduction.

- Préparer une questionnaire des compétences de la traduction et la présenter au jury pour en déduire les compétences convenables à l'échantillon de la recherche, tout en respectant les modifications du jury. 
- Elaborer et standardiser un pré-post test pour détecter à quel point les futurs enseignants maîtrisent-ils les compétences de la traduction.

- Élaborer le programme proposé basé sur l'approche pragmatique à la lueur de la communication interculturelle en suivant quelques démarches :

- Définir les objectifs généraux et spécifiques du programme.

- Préciser les sources du programme.

- Préparer le contenu du programme.

- Déterminer les stratégies proposées de l'enseignement (les activités, les exercices et les moyens d'évaluation).

- Présenter le programme proposé au jury.

- Choisir un groupe expérimental d'étudiants de la quatrième année à la section du Français dans la faculté de pédagogie de Damiette.

- Application du pré-test de la traduction aux membres de l'échantillon.

- Enseignement du programme proposé au groupe expérimental, puis application du post-test de la traduction aux membres de l'échantillon.

- Vérification des hypothèses, analyse et interprétation des résultats.

- Formulation des recommandations et offert des suggestions de la recherche.

\section{$\underline{\text { Terminologie de la recherche : }}$}

Pour définir cette notation, nous avançons d'abord certaines définitions qui ont paru dans des études antérieures, puis nous donnons notre propre définition. 


\section{L'approche pragmatique :}

- Elle est une étude des relations entre la langue et le contexte qui sont codées dans la structure de la langue. (Levinson 2000: 9)

- Elle est un des trois modes d'appréhension du langage à côté de la syntaxe qui concerne les relations entre les signes et de la sémantique qui traite du rapport des signes avec le monde. (PEIRCE, 2002 : 400)

- La Pragmatique est une toute nouvelle linguistique zone qui étudie les énoncés dans des situations données et la façon de comprendre et d'utiliser la langue à travers le contexte. ( Du ,2016:33)

Dans le cadre des définitions précédentes, le chercheur peut définir l'approche pragmatique comme suit :

Une étude ou une interprétation de la signification des énoncés de la langue à la situation dans laquelle ces énoncés sont epmoyés et non à la seule structure linguistique de la phrase utilisée.

\section{La communication cuturelle :}

- La communication interculturelle consiste en un jeu de signes et de symboles dans un contexte et un cadre déterminé difficilement réductible à leur seul contenu apparent ou immédiat. Par ailleurs, la culture fournit alors un cadre interprétatif pour les échanges. (Meier, 2004 : 155)

- La communication interculturelle est constituée par l'interaction de l'homme dans le contexte des différentes cultures. ( Shan, $2004:$ :23)

- La communication interculturelle est un processus transactionnel, symbolique impliquant l'attribution d'une 
مجلة كلية التربية بالإسماعيلية - العدد الثامن والثلاثون - مايو PV r P

signification entre personnes de cultures différentes. (Licata et Heine, 2012 : 18)

Dans le cadre des définitions précédentes, le chercheur peut adopter la définition de Licata et Heine pour la communication interculturelle parce que cette définition se convient avec la philosophie de la recherche.

\section{La Traduction :}

- Traduire, c'est substituer du textuel à du textuel, c'est aller du langage au

langage en passant par un réel déjà interprété, déjà formé en langage, déjà

constitué en œuvre. (Tatilon, 2003 : 114)

- La traduction comme un est activité de communication qui se compose de deux processus dynamiques --- le processus de décodage inférentielle et le processus de codage ( choix de decision) dans lequel trois partis (écrivain,traducteur et lecteur cible) sont impliqués et l'œuvre traduite est le produit de la interaction avec les environnements cognitifs les trois parties. (Zixia .2009:88)

- La traduction est le fait de faire passer un texte rédigé dans une langue («langue source», ou « langue de départ») dans une autre langue (« langue cible », ou « langue d'arrivée »). Elle met en relation au moins deux langues et deux cultures, et parfois deux époques. (Svenbro, 2015 : 15)

Dans le cadre des définitions précédentes, le chercheur peut définir la traduction comme suit :

Une activité de communication orale ou écrite qui comporte l'interprétation de la langue source de l'homme à une langue cible de l'autre en gardant leur cultures pour faire une interaction entre les deux. 


\section{1- L'Etude théorique}

Dans notre étude théorique, nous essayons de traiter ce sujet dans deux parties suivantes :

- La première partie est intitulée par "La traduction" qui implique les points suivants :

- La définition de la traduction.

- L'importance de la traduction dans l'enseignement du FLE.

- Les types de la traduction.

- Les approches et les stratégies pour développer les compétences de la traduction.

- La deuxième partie est intitulée par "l'approche pragmatique et la communication interculturelle " qui implique les points suivants :

- La définition de l'approche pragmatique.

- l'adaptation dans l'approche pragmatique ( nature , types, causes).

- Les étapes de l'approche pragmatique.

- la traduction et l'approche pragmatique.

\section{I- La première partie : La traduction}

\section{I.1 La définition de la traduction}

L'étude de la langue, de la culture et de la traduction et la relation entre eux est un sujet important en raison de l'importance de la communication humaine dans le monde. La variété des langues avec différentes cultures Et la nécessité de la communication dans la vie humaine a permis à la traduction 
d'être un facteur très efficace pour Communiquer, échanger des cultures et des connaissances.

Ainsi, il semble que la langue et la culture soient étroitement liées Et il est essentiel de tenir compte à la fois de la traduction. tous les traducteurs qui transmettent un sens naturel en fonction des normes culturelles et religieuses de leur société, rencontrent certaines limites et la censure à travers la traduction. (Abbasi et als, 2012 : 83)

Comme le souligne Glodjović, « la traduction est un processus qui implique la recherche de similitudes entre La langue et la culture - en particulier les messages similaires et les techniques formelles - mais on ne peut jamais à éliminer complètement ces dissemblances. Un texte traduit devrait être le site d'émergence d'une culture différente, où un lecteur aperçoit une autre culture. Une stratégie de traduction basée sur une esthétique de la discontinuité peut mieux préserver Cette différence, cette altérité, en rappelant au lecteur les gains et les pertes dans le processus de traduction et les écarts infranchissables entre les cultures.( Glodjović ,2010 :143)

Alors, traduire est défini comme le fait de faire passer un texte d'une langue à l'autre. La traduction est alors une transmission de la situation de la langue source en situation qui est son équivalent en langue cible.

Lavault définit la traduction non en termes de passage d'un texte en LD vers un texte en LA (trans) mais en termes de reproduction du message de LD (dite aussi LS ou langue source) en LA (dite aussi LC ou langue cible): La traduction consiste à reproduire dans la langue réceptrice le message de la langue source au moyen de l'équivalent le plus proche et le plus naturel, d'abord en ce qui concerne le sens et ensuite en ce qui concerne le style". (Lavault, 1985 : 11) 
Cette définition explique que le processus de la traduction passe d'abord par la compréhension du message de la langue source avant de le reproduire ou le "réexprimer" en langue cible.

D'autre part, La traduction est un acte de communication qui consiste en une mise en jeux d'un dispositif de traitement d'informations ayant pour objectif de susciter une réaction (c'està-dire amener le récepteur à concevoir des représentations pareilles à celles des locuteurs de ce message en langue source). Ce dispositif met en jeu deux dispositifs dans un schéma double : schéma simultané lorsqu'il s'agit d'une interprétation simultanée ; schéma différé, lorsqu'il s'agit d'une traduction d'une œuvre écrite. (KAMBAJA, 2009 : 9)

Cette définition voit que le traducteur traite des informations et les transmet au moyen du langage verbal, plaçant et replaçant chacun de ses énoncés dans un contexte.

Pour sa part, Zixia (2009 : 91) définit la traduction comme "une opération de métacommunication assurant l'identité de la parole à travers la différence des langues". La traduction est considérée comme une renonciation d'un message tel qu'on l'a compris en langue source. Et de manière explicite, toutes s'accordent pour situer la traduction au niveau de la parole (le message) et non au niveau de la langue.

La traduction, désormais, est considérée une traduction littérale qui porte sur le contenu d'un acte de parole. Alors l'énoncé « it rains cats and dogs » se traduit heureusement.

Donc, le traducteur exprime ce qu'il a compris, c'est-à-dire le vouloir dire qu'il attribue au locuteur, telle est la dernière explication que nous voulions apporter en présentant notre modèle. Cette conception est fort proche de la définition interprétative dans laquelle nous nous inscrivons : "Le processus de la traduction consiste à dégager, de la formulation en langue source, le sens qu'elle désigne mais qui n'est pas contenu en elle, puis à l'exprimer en langue cible ". (Léderer et Seleschovitch, 2001: 105 ) 
Enfin, on peut définir la traduction comme une activité de communication orale ou écrite qui comporte l'interprétation de la langue source de l'homme à une langue cible de l'autre en gardant leur cultures pour faire une interaction entre les deux.

\section{I.2 L'importance de la traduction dans l'enseignement du FLE}

La traduction a toujours été une pratique répandue à travers les époques. Les sources historiques de la traduction sont constituées par des textes sacrés. L'accès à la parole divine était l'un des premiers besoins de l'être humain dans les sociétés d'antan. Cet accès se faisait ou par l'accès direct au texte original ou par la traduction de celui-ci. La traduction grecque de 1'Ancien Testament et la traduction latine de la Bible par Saint Jérôme puis les travaux d'E. Nida, toujours sur la traduction de la Bible constituent les premiers travaux de ce genre. (MARZOUK, 2013 : 93)

De plus, la traduction est devenue le seul moyen aux mains de ces Etats pour se comprendre. Ces institutions se trouvent ainsi dans l'obligation de traduire dans toutes ces langues ou au moins dans les 77 principales d'entre elles . On imagine alors le besoin des traducteurs que de nombreux centres et universités à travers le monde se chargent de former. (Elfoul : 2006, 113)

Par rapport, toutes les études récemment effectuées sur le processus d'acquisition d'une langue étrangère considèrent qu'il existe un mécanisme général qui fait appel à la langue maternelle et qui échappe à la conscience de l'apprenant. Des chercheurs parlent de l'existence de langues intermédiaires : un ensemble de structures et valeurs sémantiques transférées d'une langue bien connue à une autre moins connue. La traduction, qu'on le veuille ou non, joue un rôle important dans la structuration et l'évolution de ces langues intermédiaires qui facilitent l'apprentissage d'une langue étrangère. (Farah, 2015 : 10) 
Pendant longtemps, la traduction a dominé dans l'enseignement/apprentissage des langues étrangères. Les méthodologies avec la traduction préconisaient ce détour par la langue maternelle de l'élève avant que les méthodologies sans traduction l'interdisent en faveur d'un accès direct à la langue étrangère. Dans les méthodologies d'enseignement du XIXème et $\mathrm{du}$ début du XXème siècle la traduction avait un rôle très important en classe de langue étrangère. Ensuite, les méthodes d'enseignement ont refusé le recours à la langue maternelle en classe de langue étrangère. A présent dans les méthodes, la traduction est revenue de nouveau dans sa place en classe de langue étrangère. Mais il y a toujours des professeurs qui sont contre de l'exploiter en classe de langue étrangère. Pour certains d'eux ils pensent que l'utilisation de la langue maternelle en classe de langue étrangère c'est un empêchement de découvrir la langue étrangère et sa culture. De la même manière cette recours n'est pas utile pour apprendre une langue étrangère. (Ballard, 2009 : 143)

La traduction ne montre pas les procédés et les techniques mises en œuvre dans l'esprit des traducteur pendant le processus de la traduction mais elle reflète la pratique exclusive des traducteurs.. on s'intéresse seulement à la matière en langue de départ et le résultat en langue cible.

D'ici, on peut limiter l'importance de la traduction pédagogique en classe de langue à : valoriser les savoir-faire chez les apprenants ; aider les apprenants à comprendre les locutions et les expressions idiomatiques; développer les compétences des deux langues chez les apprenants.

\subsection{Les types de la traduction}

Beaucoup de chercheurs et pédagogues comme (Gisèle 2008 ; Lindenberg et Vegliante 2011 \& Swaan 2013) s'accordent que sur le marché du travail, on peut distinguer la traduction en deux 
types: la traduction de textes techniques et la traduction littéraire. La majorité des traducteurs professionnels traduisent des textes techniques. Les traducteurs littéraires sont attachés à une maison d'édition ou autoentrepreneurs.

\subsubsection{La Traduction technique :}

La traduction technique concerne les documents tels que les manuels, feuillets d'instructions, notes internes, procès-verbaux, rapports financiers, et autres documents destinés à un public limité (celui qui est directement concerné par le document) et dont la durée de vie utile est souvent limitée.

Par exemple, un guide d'utilisation pour un modèle particulier de réfrigérateur n'a d'utilité que pour le propriétaire du réfrigérateur, et restera utile tant que ce modèle de réfrigérateur existera. De même, la documentation logicielle s'adresse généralement à un logiciel particulier, dont les applications concernent une catégorie d'utilisateurs.

La traduction de textes techniques exige souvent des connaissances spécialisées dans un domaine particulier. On compte parmi les textes techniques :

- Les documents d'ordre technique (informatique, électronique, mécanique, etc.) ;

- Les textes scientifiques (biologie, médecine, astronomie, médecine, géologie, etc.) ;

- Les textes d'ordre financier, juridique ou administratif. La traduction administrative s'est particulièrement développée après la Seconde Guerre mondiale.

La traduction technique est un type de traduction souvent « anonyme » dans lequel le nom du traducteur peut ne pas être associé au document traduit, tout comme certaines entreprises ne font pas mention des auteurs des guides d'utilisation des produits. Cependant, dans le cas de la traduction de livres à contenu 
informatif, le traducteur sera mentionné dans la section de responsabilité primaire de l'item bibliographique du livre.

\subsubsection{La Traduction littéraire :}

Ce type de traduction concerne les romans, poèmes et autres genres du domaine littéraire. La traduction littéraire demande des aptitudes en stylistique, une bonne imagination et des connaissances culturelles étendues. Il s'agit de reproduire l'effet intégral du texte original chez le lecteur en langue d'arrivée, autant que le sens des mots. La traduction doit être aussi plaisante à lire et susciter les mêmes émotions que l'original, suivant l'adage de Cervantès : « ne rien mettre, ne rien omettre ». Les grands traducteurs, quelle que soit la langue, ont une formation très exigeante, études littéraires et universitaires, dans la langue dans laquelle ils traduisent - et grand nombre de traducteurs littéraires traduisent de plusieurs langues - mais aussi et surtout dans leur langue maternelle, langue vers laquelle ils traduisent. L'écriture du texte de destination devient alors primordiale.

En poésie, la traduction offre une double difficulté s'il faut rendre compte à la fois du sens et de la métrique (de la forme en général[24]), voire de procédés rhétoriques[25]. Si l'on se limite au sens (sémantique), un exercice de traduction de haïkus, après passage dans plusieurs langues et retour final au français, a permis de démontrer une assez grande robustesse du contenu sémantique.

En général, la traduction technique est plus accessible et rapporte un salaire plus élevé que la traduction littéraire. Cette dernière est effectuée avant tout par amour de la langue et du texte original, ou par volonté de faire connaître toutes les subtilités d'un texte admirable écrit en langue étrangère. 
1.4 Les stratégies et les approches pour développer les compétences de la traduction

Il existe de nombreuses stratégies et approches explicatives de la traduction. Chaque stratégie ou approche se caractérise, en règle générale, par une terminologie propre, des catégories spécifiques et une méthodologie distincte. On peut distinguer aussi des courants différents dans une même stratégies ou approche. La combinaison des plusieurs stratégies ou approches ne peut qu'enrichir la traductologie. (AGUADO et PEREZ, 2005 : 300)

\subsection{1 les stratégies de traduction}

VAN DYK (2007) évoqué l'ensemble des différentes stratégies possibles pour que les apprenants parviennent à enrichir leur répertoire de stratégies.

\subsubsection{Evitement}

L'évitement ne constitue pas vraiment une stratégie mais plus un comportement dont l'intérêt pédagogique et communicatif serait nul ou très limité. S'il s'avère utile dans le cadre de l'expression quotidienne, auquel cas on a non seulement tendance à esquiver fréquemment les difficultés d'ordre linguistique, mais on évite aussi carrément certains sujets pour diverses raisons, il ne s'agit pas d'une stratégie à encourager pour l'apprentissage d'une langue, et encore moins pour la traduction. Bien que toutes les stratégies qui consistent à éviter la prise de risque puissent s'avérer utiles dans une certaine mesure, notamment lors d'un examen, nous les considérons comme fort regrettables dans le cadre de cette recherche, car elles sont susceptibles de déboucher sur une traduction trop littérale. Nous 
souhaitons au contraire que les étudiants se libèrent du texte de départ et qu'ils formulent leurs énoncés de manière spontanée sans prendre appui sur la langue source.

\subsubsection{Transfert}

Nous nous sommes déjà longuement attardés sur ce comportement qui, tout comme l'évitement, pourrait dans de rares cas contribuer à la communication de tous les jours, notamment pour éviter des pannes. De même, lorsque cette stratégie implique une réflexion et une déduction grâce aux connaissances des autres langues, elle est hautement bénéfique en tant que stratégie d'apprentissage. Néanmoins, nous avons argumenté ce comportement ci-dessus : le transfert automatique d'une langue vers une autre entraîne des interférences et la traduction, mentale ou réelle, constitue selon cette méthode une traduction formelle qui manque d'idiomaticité ou qui souffre d'inintelligibilité. Nous avons mentionné auparavant la méthode de stylistique comparée qui ne permet pas, selon nous, de rompre avec cette opération de transfert. Admettons qu'une telle pratique comporte un intérêt linguistique, elle ne devrait pas être encouragée en tant que stratégie de traduction.

\subsubsection{Réduction}

Les auteurs identifient cette stratégie comme non négligeable lors de toute conversation. L'information jugée superflue peut être supprimée et la compétence pragmatique du locuteur lui permet d'ailleurs d'adapter la forme de son message en fonction de son interlocuteur et de la situation. Il en va de même pour la traduction. Si certaines informations connues du public peuvent être supprimées, de même que toute information redondante, surtout sous contraintes (cf. l'interprétation), cette opération de 
suppression doit être menée avec précaution pour éviter une perte d'information. Tout comme l'évitement, cette stratégie utilisée en cours de traduction peut empêcher les étudiants d'apprendre à surmonter les obstacles et d'exploiter toutes leurs ressources linguistiques.

\subsubsection{Réexpression}

Contrairement aux stratégies d'évitement et de transfert, des stratégies de réalisation permettent non seulement de faire des traductions de bonne qualité et fidèles au sens, mais elles développent également la compétence communicative. Une fois que les étudiants ont pris conscience du danger du transfert, il faut absolument leur apporter d'autres moyens de se prémunir contre des ruptures dans la communication, et ceci grâce à des stratégies dites « compensatoires ». Ce paragraphe nous conduit enfin à l'analyse des principales stratégies auxquelles les étudiants sont censés avoir recours lors de la traduction à vue pour résoudre les obstacles de sens et de langue. Pour illustrer cette liste, nous lui avons ajouté d'un certain nombre d'exemples puisés dans notre expérience empirique. S'il est impératif d'encourager les étudiants à adopter ces stratégies, une grande vigilance est néanmoins de mise, car certaines de ces stratégies peuvent avoir un impact sur la qualité du message tandis que d'autres débouchent sur une perte d'information, comme c'est le cas parfois avec la stratégie de simplification ou de généralisation.

\subsubsection{Anticipation}

Outre les tactiques mentionnées ci-dessus, il existe d'autres stratégies auxquelles tout être humain a inévitablement recours. Déjà évoquée dans les chapitres précédents, l'anticipation est une technique qui dépend de la compétence pragmatique et elle 
est essentielle pour la traduction à vue où le temps de lecture est limité et où il faut absolument procéder par une lecture globale, en identifiant notamment les mots clés et les liens logiques, les plus grands porteurs de sens, en négligeant donc certaines structures ou certains termes plus ou moins redondants. Une telle lecture implique donc la capacité à faire des suppositions quant aux mots les plus susceptibles d'être présents dans ce contexte linguistique et extralinguistique précis. L'anticipation permet donc aux « unités de sens » de « fusionn[er] progressivement en des sens plus vastes, non sur le modèle d'une progression continue ou 2 linéaire mais par une série de sauts.

\subsubsection{Prise de risques}

Bien que le recours à certaines stratégies vise à éviter des erreurs, il peut en entraîner d'autres, en particulier celles qui impliquent une prise de risque. Il ne reste pas moins que l'intérêt pédagogique d'une telle démarche d'apprentissage et de traduction en cours est considérable et une plus grande prudence ne serait de mise qu'en cas d'évaluation notée. Hors situation d'examen, cette aptitude langagière est une stratégie d'apprentissage incontournable. La situation pédagogique exolingue du français accentue ce besoin de " tester » des énoncés que l'on n'a pas appris explicitement et qui, de préférence, s'écartent formellement de leurs équivalences dans les langues de référence des apprenants. De plus, celui qui saura inventer des mots ou des tournures grâce à sa compétence métacommunicative pourra ainsi se prémunir contre les blocages. Or, il faut bien distinguer l'emploi des calques phonologiques de l'invention des mots. Bien que l'emploi de ces barbarismes implique la création d'un mot qui n'existe pas, donc théoriquement d'une invention (par exemple *extender pour extended), un tel calque ne constitue en rien un raisonnement intelligent, ni un comportement de réalisation. 


\subsection{2 les approches de traduction}

Kulczycka et Wolna.(2014) présentent quelques approches pour développer les compétences de la traduction comme suit :

\subsubsection{L'approche linguistique}

La relation entre linguistique et traduction peut être résumée de 2 orientations principales :

- les acquis de la linguistique peuvent être appliqués à la pratique de la traduction

- la théorie linguistique peut se développer grâce à la traduction pratique.

Aujourd'hui c'est clair que la linguistique s'intéresse aux langues et au langage tandis que la traduction s'occupe des traducteurs et des traductions. Il y a plusieurs courants linguistiques et chacun propose une explication propre et des techniques spécifiques, parce que chacun envisage les phénomènes observés à un niveau différent: le «mot», la "phrase » ou encore le «texte». La linguistique joue un rôle moteur dans le développement de la traductologie et en même temps elle présente certaines inconséquences qui créent le fossé entre ces deux disciplines.

\subsubsection{L'approche "linguistique appliquée "}

La linguistique appliquée est une branche de la linguistique qui s'occupe davantage des applications pratiques de la langue.

- «La traduction est une opération réalisée sur les langues : un processus de substitution d'un texte dans une langue par un texte dans une autre langue »

-cette distingue certaines types de traduction : 
a) La traduction «intégrale» par opposition à la traduction «partielle »

b)La traduction «totale» par opposition à la traduction « restrictive »

- La critique : cette approche a été critiquée pour deux raisons :

a) Tous les traductologues sont sûrs que la traduction «totale » n'existe pas.

b) Cette approche ne contient pas la dimension «dynamique »de la traduction.

\subsubsection{L'approche sociolinguistique}

La sociolinguistique examine la langue dans son contexte social à partir du langage concret. Elle s'est formée dans les années 1960 aux Etats-Unis et s'occupe aussi des différences socioculturelles, des politiques linguistiques et de l'économie de la traduction.

- le caractère vague du terme « la traduction » qui est décrit dans 3 acceptions de la traduction :

a) Le terme désigne un "résultat»- le texte traduit est une traduction.

b) Le terme désigne une «opération »- l'opération de reformulation mentale est une traduction.

c) Le terme désigne une "comparaison » - les deux objets comparés sont des traductions.

- Le refus du recours exlucif à la linguistique dans l'étude de la traduction.

\subsubsection{L'approche textuelle}

Cette approche demande que la traduction doit être Précédée d'une analyse textuelle pour assurer bonne compréhension.

\section{La traduction peut être déterminée par:}


a. Le type de texte

b. La fonction envisagée pour le texte

c. La finalité du texte (le but)

d. Le sens du texte

e. Le contexte ou le cadre du texte

f. L'idéologie du texte

Grâce à la multitude des points de vue, une approche discursive de la traduction est plus en plus populaire parmi les traductologues. Selon Delisle, l'analyse du discours permet de se concentrer au sens en deux niveaux principaux:

- niveau du genre

- niveau du texte

2. Les phénomènes textuels- ce sont des phénomènes que le traducteur doit savoir détecter pour pouvoir traduire de façon correcte :

- a. L'intertextualité - ce sont les liens entre les textes et leurs registres différents.

- b. Les modes d'expression de la sociabilité qui diffèrent d'un group humain à l'autre

- c. Les visions du monde diverses

- d. La métaphorisation - les métaphores ce sont des marqueurs de visions culturelles et de points de vue idéologiques.

\subsubsection{L'approche pragmatique}

- La pragmatique est l'étude du langage du point de vue de ses buts et des conditions d'utilisation et se concentre sur les expressions qui produisent un effet ( les ordres, les requêtes, les excuses, les compliments). 
Cette approche vise à produire dans la langue cible des actes «locutoires" et «illocutoires" ayant le même force «perlocutoire» que ceux de la langue source.

- grâce à l'approche pragmatique dans la translation le traducteur acquiert une conscience de l'importance du sens perçu par interlocuteur. Ce sens est le résultat d'une séquence appréhendée dans un texte- la même séquence peut être comprise différemment selon le type de texte( argumentatif, informatif...)

Une telle approche est propice à la pratique de la traduction au sens large, et d'autant plus de la traduction en cours de langue. En effet, tout refus d'une conception linguistique de la traduction s'ouvre à une approche contextuelle ou pragmatique de la traduction, car elle permet d'introduire une dimension de plus dans laquelle la traduction du sens s'inscrit inéluctablement et tout naturellement. Dans la situation didactique qui est notre préoccupation prioritaire, la traduction à vue repose largement sur cette compétence pragmatique pour saisir le sens et pour combler les lacunes linguistiques.

\section{II- La deuxième partie : l'approche pragmatique à travers la communication interculturelle}

\section{II.1 La définition de l'approche pragmatique.}

La pragmatique est née dans le cadre de la linguistique. Plus précisément, c'est Charles Morris qui utilise le terme pour la première fois et le définit à partir des concepts peirciens comme l'étude de la relation des signes à leurs interprétants. Ce sont cependant les influences réciproques entre philosophie du langage, sémiotique et linguistique qui rendent compte de la richesse des théories pragmatiques. (Totschnig, 2000 : 110) 
La pragmatique est donc concernée par l'usage que nous faisons du langage. Il s'agit de montrer comment une grande partie de l'activité communicationnelle consiste à situer sa parole vis-à-vis de celles des autres, et comment le sens des énoncés dépend dans une large mesure des positions respectives des interlocuteurs à l'intérieur d'un échange conversationnel. (Peirce, 2002 : 12)

D'ici, la pragmatique se représente un mouvement dans l'ensemble des sciences humaines et sociales en suivant la théorie de la communication humaine et la reconnaissance à la relation entre la langue entre la société. La langue n'est pas seulement un moyen de communication mais un groupe de rapports humains.

Par rapport, la pragmatique prenant en considération les actes de paroles, construit du même coup des sujets s'impliquant dans la communication, occupant des « places », jouant des « rôles ». Ce sont donc des sujets qui interagissent et s'obligent mutuellement. (Zixia, 2009 : 90)

$\mathrm{Au}$ cours des vingt dernières années, des perspectives différentes sont apparues sur la Pragmatique avec diverses définitions proposées par les linguistes: la Pragmatique est l'étude des relations entre la langue et le contexte qui sont codées dans la structure de la langue en gardant la communication humaine telle que déterminée par les conditions de la société .( Du, 2016 : 33)

Sperber et Wilson ajoutent que la Pragmatique est une capacité de l'esprit, une type de système de traitement de l'information, un système d'interprétation d'un phénomène particulier dans le monde, à savoir le comportement communicatif humain. (Sperber \&Wilson, 2003 : 183).

Autrement, la Pragmatique est une nouvelle branche de la linguistique qui aborde les énoncés dans des situations données en concentrant sur le contexte de la langue. 
D'autre coté, la Pragmatique est une perspective cognitive, sociale et culturelle générale sur les phénomènes linguistiques par rapport à leur utilisation dans des formes de comportement. L'approche pragmatique permet ainsi une interrogation de l'objet qui doit permettre d'aller au-delà de la « parole sociale » pour atteindre le Co-interlocutif. (Verchueren, 2000: 7)

A la lumière de cela, on peut définir l'approche pragmatique comme une étude ou une interprétation de la signification des énoncés de la langue à la situation dans laquelle ces énoncés sont epmoyés et non à la seule structure linguistique de la phrase utilisée.

\section{II.2 l'adaptation dans l'approche pragmatique (nature, formes, raisons)}

L'adaptation est le processus, créateur et nécessaire, d'expression d'un sens général visant à rétablir, dans un acte de parole interlinguistique donné, l'équilibre communicationnel qui aurait été rompu s'il y avait simplement eu traduction. Ou plus simplement : l'adaptation est le processus d'expression d'un sens visant à rétablir un équilibre communicationnel rompu par la traduction. (Real et Al., 2001 : 791)

Il est vrai que l'adaptation maintient l'équilibre communicationnel qu'une traduite littérale romprait, mais - et principalement pour les œuvres littéraires - nous ne pensons pas qu'il en soit toujours ainsi. L'adaptation peut aussi répondre à une stratégie privilégiant la dimension fictionnelle du texte. (Samara, 2003 : 308)

Donc, on ne peut pas séparer clairement entre la traduction et l'adaptation parce que ces deux opérations visent à établir un acte de communication réel. l'adaptation est toutefois considérée comme un type ou une forme de traduction. 
L'adaptation pragmatique se réfère à la modification de quelques éléments de source texte "qui ne fonctionnerait pas bien dans la langue cible "pour les faire se rencontrent les besoins $\mathrm{du}$ nouvel environnement culturel et linguistique. (Vehmas, 2002 : 99 - 100)

PEIRCE fournit une autre définition pour l'adaptation pragmatique en allant à suggérer que le terme peut également être considéré pour faire référence à des changements de sens informatif d'un certain élément de texte cible en raison de facteurs situationnels. (PEIRCE, 2007 : 229)

De plus, l'adaptation pragmatique se réfère à la modification du contenu ou la forme du texte source afin de produire un texte cible qui est conforme aux exigences de la nouvelle situation de communication. (Kosonen, 2011: 61)

L'adaptation pragmatique est une réponse aux nécessités de la langue cible et une outil vital aux difficultés des changements culturels. Cette adaptation permet à dépasser la traduction littéraire.

D'autre part, les adaptations pragmatiques sont l'illustration éclatante de l'importance et de la nécessité de la créativité dans le processus de traduction littéraire, que ce soit pour suggérer en deux mots une atmosphère de fête ou pour rendre un trait d'humour. (Musampa, 2009 : 42)

C'est pour cela, on peut aborder l'adaptation comme une réécriture du texte source en fonction de la situation de la culture cible.

Selon (Kosonen 2011), il existe quatre types de l'adaptation pragmatique: ajouts, omissions, substitutions et modifications d'ordre. Cependant Les quatre types d'adaptation pragmatique peuvent être définis comme suit :

- L'addition se réfère simplement à ajouter de quelque chose dans le texte. L'addition peut être nouvel élément de tout type (par exemple une image ou un morceau de texte) et la taille (par 
exemple une ponctuation, une marque, un mot, une phrase, une clause ou un paragraphe) ou il peut être une supra-segmentaire tels que l'italique ou gras.

- L'omission fait référence à supprimer les similitudes. La Substitution se réfère à remplacer, par exemple, l'un des éléments avec un autre élément, et encore une fois, les éléments peut être de tout type et de la taille.

- La substitution peut coïncider avec l'addition ou l'omission (ou les deux), si, par exemple, un paragraphe entier est remplacé par un autre paragraphe.

- La modification ou le changement de l'ordre se réfère à une adaptation qui conserve tous les éléments, mais les réarrange. Encore une fois, le genre et la taille de ces éléments peut varier; le changement peut affecter la macrostructure d'un tout texte ou une seule phrase.

Vehmas-Lehto (2002: 101) suggère que les adaptations pragmatiques peuvent être faites en raison de diverses différences dans les facteurs extratextuelles du texte source et le texte cible. Ces facteurs interdépendants comprennent largement le temps, le lieu, et la fonction, ainsi que la culture, la connaissance et les conventions (qualitatives ou quantitatives) des lecteurs.

Les causes possibles de l'adaptation pragmatique pourrait être dire ce qui suit: les différences de participants, les différences en place et le temps, et les différences dans la fonction de texte. Etant donné que les différences de les participants comprennent les différences de motif et l'intention, ainsi que les différences de public visé et de leur culture, et la connaissance du monde, etc. Cette liste comprend tous les huit facteurs extratextuelles.

\section{II.3 La philosophie et Les stratégies de l'approche pragmatique.}

Selon Chesterman, les stratégies représentent des standard de solution à un manque de correspondance entre les objectifs et les 
moyens; elles sont utilisés lorsque les moyens qui apparaissent d'abord être à portée de main semblent être insuffisants pour permettre au Traducteur pour atteindre un objectif donné " ajoute qu'une stratégie peut être soit, les stratégies mondiales ou globales applicables à $l^{\prime}$ ensemble du texte et des stratégies locales pour un morceau de texte spécifique. (Chesterman, 2009: 82)

Chesterman et Wagner (2014 : 60-63) limitent les catégories de stratégies textuelles : les stratégies syntaxiques qui se réfèrent aux changements syntaxiques, les stratégies sémantiques qui concernent le sens lexical, figuratif et thématique, et les stratégies pragmatiques qui représentent la sélection de l'information dans le texte cible.

\section{1- Filtrage culturel}

Cette stratégie est également appelée la naturalisation, domestication ou adaptation. Il décrit la manière de traduire le texte original en langue cible en particulier les aspect culturels ou, de sorte qu'ils sont conformes aux normes de la langue cible. La procédure inverse, de sorte que par exemple les textes ne sont pas adaptés de cette manière, mais sont, par exemple, empruntés ou transférés.

\section{2- Changement d'explicitation}

Changements soit vers (explicitation) ou vers (implication). Explicitation rend certaines informations explicites qui est seulement implicite dans l'original. Implication omet les informations que les lecteurs cibles peuvent être raisonnablement prévues pour déduire.

\section{3- Changement des 'informations}

Soit l'ajout de nouvelles informations (non-inferrable) qui sont pertinentes pour le lectorat cible, mais ne sont pas présents dans 
le texte intégral ou l'omission de quelques informations de texte source considérée comme non pertinente .

\section{4- Changement interpersonnel}

Ces changements affectant le niveau de formalité, le degré d'émotivité et la participation, etc. (Par exemple les débuts et fins de lettres).

\section{5- Changement illocutoire}

Les changements d'acte de parole, par exemple impliquant un changement de la Mode du verbe de l'indicatif au impératif, les changements dans l'utilisation des questions et des exclamations rhétoriques, changements entre le discours direct et indirect.

\section{6- Changement de cohérence}

Ces modifications traitent à l'arrangement logique de des informations dans le texte, par exemple, en paragraphe.

\section{7- Traduction partielle}

Cela couvre tout type de traduction partielle, comme la traduction résumée, la transcription, la traduction des sons seulement.

\section{8- Changement de visibilité}

ces changements concernent l'état de la présence d'auteur, ou ; par exemple Les notes du traducteur, commentaires entre crochets (tels que des explications sur les jeux de mots).

\section{9- Trans rédaction}

ces changements impliquent la réédition du texte source, par exemple parce qu'il est mal écrit.

\section{0- $\quad$ Autre changements pragmatiques}

Par exemple, les changements d' mise en page ou le choix du dialecte. 


\section{II.4 la traduction et l'approche pragmatique}

L'étude de la langue, de la culture et de la traduction et la relation entre eux est un sujet important en raison de l'importance de la communication humaine dans le monde. La variété des langues avec différentes cultures et la nécessité de la communication dans la vie humaine ont permis à la traduction d'être un facteur très efficace pour Communiquer, échanger des cultures et des connaissances. Ainsi, il semble que la langue et la culture soient étroitement liées et il est essentiel de tenir compte à la fois de la traduction. Tous les traducteurs qui transmettent un sens naturel en fonction des normes culturelles et religieuses de leur société, rencontrent certaines limites et la censure à travers la traduction. (Abbasiet als ,2012:83)

Comme le souligne Glodjović «la traduction est un processus qui implique la recherche de similitudes entre La langue et la culture - en particulier les messages similaires et les techniques formelles - mais on ne peut jamais à éliminer complètement ces dissemblances. Un texte traduit devrait être le site d'émergence d'une culture différente, où un lecteur aperçoit une autre culture. Une stratégie de traduction basée sur une esthétique de la discontinuité peut mieux préserver Cette différence, cette altérité, en rappelant au lecteur les gains et les pertes dans le processus de traduction et les écarts infranchissables entre les cultures. ( Glodjović ,2010 :143)

Lafeber Confirme que les traducteurs ont besoin de plus que des compétences linguistiques: en plus de Des connaissances générales et parfois spécialisées, elles ont besoin des compétences d'analyses, de recherches, de technologies, Compétences interpersonnelles et organisationnelles, compétences socioculturelles et compétences pragmatiques. (Lafeber, 2012 : 125) 
La compétence de traduction comprend des compétences spécifiques telles que La compétence linguistique, la compétence en matière de texte, la connaissance de la matière, la compétence culturelle et la compétence de transfert.

La compétence de transfert joue un rôle actif dans la traduction des textes dans la langue cible; couvre également les méthodes de traduction et les techniques nécessaires à la gestion de la tâche de traduction rapidement et efficacement. Sans compétence de transfert, les traducteurs ne parviennent pas à effectuer le rendu dans la langue cible.

Il est clair que l'adaptation pragmatique et la traduction vont souvent main dans la main. Car l' Adaptation tend à être une partie importante de la traduction La principale raison pour la relation entre l'adaptation pragmatique et la traduction est la relation étroite entre la culture et langue. Après tout, l'adaptation pragmatique traite souvent à la culture Bien que la traduction concerne la langue. (Nord, 2005 : 28)

Selon Barekat, on peut distinguer quatre différents types de problème de traduction: problèmes de traduction pragmatiques, problèmes liées à une convention, les problèmes de traduction linguistiques et problèmes spécifiques au texte. (Barekat, 2013 : 205 )

D'ailleurs, on mentionne un autre aspect central de l'approche pragmatique en assurant que les adaptations pragmatiques sont considérées comme des solutions aux problèmes de traduction qui concernent les facteurs situationnels.

Ruschiensky soutient que la traduction est un processus dynamique dans lequel l'adaptation doit être effectuée. Ils conviennent que le choix de la langue cible doit être adapté au contexte culturel différent. Le texte cible doit également s'adapter au contexte source et la structure linguistique au l'expression fidèle de l'intention de l'auteur original aussi que le texte cible doit être adaptée aux besoins du contexte cible pour réussir la communication interculturelle (Ruschiensky , 2015 : 28-33) 
La culture influence la manière dont les gens perçoivent et conceptualisent le monde. Très souvent, la culture pose des Restrictions sur leurs choix de significations lexicales. Par conséquent, le traducteur doit adapter son choix au sens lexical en conséquence, de sorte que l'intention communicative du locuteur / écrivain peut être à juste titre Transmis au lecteur cible.

La Culture et langue s'interagissent. L'influence culturelle sur la façon dont les gens utilisent la langue et la langue est une Reflet de la culture. Face aux différences dans l'utilisation des langues causées par la culture, le traducteur doit décider À quel contexte culturel il / elle devrait s'adapter. Sa décision aura un impact sur son choix de stratégie de traduction . Ceci est particulièrement vrai au cas de des proverbes, des expressions spécifiques à la culture Et des métaphores. La compétence pragmatique est la capacité de communiquer efficacement qui implique à la fois des compétences grammaticales et Connaissance pragmatique.

La compétence pragmatique se compose de deux aspect : Compétence illocutoire qui nous permet d'utiliser le langage pour exprimer un large éventail de fonctions, et pour interpréter la force illocutoire des énoncés ou du discours; et compétence sociolinguistique qui nous permet Pour exécuter des fonctions linguistiques de manière appropriée à ce contexte.

\section{Conclusion :}

Pour conclure, nous disons que la traduction n'est pas une opération portant sur les langues, elle est une réexpression d'un contenu compris selon le contexte (ou les contextes). La compréhension dont il s'agit est le résultat de l'application d'une certaine interprétation basée sur le principe de pertinence. 
La traduction est un acte de communication qui doit être étudiée sous un angle pragmatique, lequel prend en compte les aspects sémantiques, cognitifs, logiques, et encyclopédiques.

La pragmatique, en tant qu'étude de l'usage contextuel du langage, est une discipline utile à la traduction car cette approche inférentielle sur la compréhension du message à traduire, sur l'interprétation de ce message par le traducteur, sur le processus lui-même de traduction et sur le contexte. La traduction ne peut que s'inspirer de la pragmatique et d'autres courants de la sémantique.

\section{2-L'Etude Expérimentale}

Etant donné que notre étude vise à déterminer l'efficacité d'un programme proposé basé sur l'approche pragmatique à la lueur de la communication interculturelle pour développer les compétences de la traduction chez les futurs enseignants du Français à la Faculté de pédagogie. Le chercheur a élaboré une liste des compétences de la traduction et un test de traduction visant à évaluer ces compétences chez les les futurs enseignants du Français à la Faculté de pédagogie.

\section{$\underline{\text { 2.1.1 Les objectifs de la liste : }}$}

Cette liste vise à déterminer les compétences de la traduction nécessaires aux futurs enseignants du Français à la Faculté de pédagogie.

\section{$\underline{\text { 2.1.2 Les sources de la liste : }}$}

Pour préparer cette liste, le chercheur a recours aux sources suivantes : 
- les études et les recherches antérieures qui ont abordé la traduction et ses compétences.

- Les analyses théoriques contenues dans les références suivantes :

1- Abbasi ,G; zadeh,S • Assemi.A ., Dehghan,S.(2012). Language, Translation, and Culture, Singapore, IACSIT Press.

2- Gile, D.(2005). La traduction. La comprendre, l'apprendre, Paris, Presses universitaires de France.

3- Guidere ,M. (2010). La traduction à la trauductologie , paris, DeBoek.

4- Tsatourova, I.A., Kashirina, N.A. (2008). Analyse traductologique du texte, langue anglaise. Manuel avec le support didactique, Saint-Petersbourg, Perspektiva.

\section{$\underline{\text { 2.1.3 La description de la liste des compétences de la }}$ traduction :}

La liste des compétences de la traduction comporté 15 compétences nécessaires aux futurs enseignants du Français à la Faculté de pédagogie. Devant chaque compétence se trouve le degré d'importance (très important - important - peu important).

\subsection{Elaboration du test de traduction :}

Pour déterminer l'efficacité d'un programme proposé basé sur l'approche pragmatique à la lueur de la communication interculturelle pour développer les compétences de la traduction chez les futurs enseignants du Français à la Faculté de pédagogie. 
Le chercheur a préparé un test de traduction en suivant les étapes suivantes :

2.2.1 Identification des objectifs du test.

2.2.2 Détermination des sources du test.

2.2.3 Description du test.

2.2.4 Passation du test :

2.2.4.1 Choix de l'échantillon.

2.2.4.2 Durée du test.

2.2.4.3 Fidélité du test.

2.2.4.4 validité du test.

2.2.4.5 notations du test.

\subsubsection{Les objectifs du test :}

\subsubsection{1 objectif général :}

Ce test vise à évaluer l'efficacité d'un programme proposé basé sur l'approche pragmatique à la lueur de la communication interculturelle pour développer les compétences de la traduction chez les futurs enseignants du Français à la Faculté de pédagogie..

\subsubsection{2 objectif spécifique :}

Notre test de traduction a pour but d'évaluer chez les futurs enseignants à la faculté de Pédagogie les compétences suivantes :

- Saisir la langue de départ et la langue d'arrivée.

- Maîtriser exactement des terminologies et des concepts dans la langue de traduction.

- Choisir le style convenable pour les nouveaux concepts.

- Comprendre des sujets complexes et élaborer le sens des textes obscurs.

- Détecter les contradictions des incohérences, le non-sens et les erreurs logiques, ou les faits.

- Avoir une bagage linguistique étendu dans la langue cible. 
- Connaitre les aspect culturelles de texte cible.

- Mettre en considération les aspects sociolinguistique et pragmatiques pendant la traduction.

\subsubsection{Détermination des sources du test :}

Pour préparer le test, le chercheur a révisé de ce qui suit :

- les études et les recherches antérieures qui ont abordé la traduction.

- Les ouvrages comme les livres, les magazines et les articles qui ont évalué la traduction.

\section{$\underline{\text { 2.1.3 Description du test : }}$}

Après avoir limité les objectifs et les sources du test, on a mis les questions de ce test pour évaluer le degré de maitrise des compétences variées de la traduction chez les futurs enseignants à la faculté de Pédagogie avant et après l'application du programme proposé basé sur l'approche pragmatique à la lueur de la communication interculturelle.

$\mathrm{Ce}$ test comprend quatre questions portant sur les compétences de la traduction choisies. On compte 20 notes pour chaque question. Donc la note totale du test est 100 notes.

Les cinq questions ont comporté les situations suivantes de la traduction :

\section{1- Traduisez le texte ci-dessous de la langue française à la langue arabe.}

\section{2- Traduisez le texte suivant de la langue arabe à la langue française en français.}


3- Traduisez le sujet suivant de la langue française à la langue arabe.

\section{4- Traduisez le sujet suivant de la langue française à la langue arabe.}

\section{5- Traduisez les proverbes suivants de la langue française à la langue arabe et le contraire.}

\subsubsection{Passation du test :}

Avant la passation du test, le chercheur définit les points suivants :

\subsubsection{Choix de l'échantillon :}

L'étude expérimentale de notre étude se sert d'un seul groupe parmi un échantillon d'étudiants de la quatrième année à la section du Français dans la faculté de pédagogie de Damiette.

\subsubsection{Durée du test :}

On a calculé le temps du test en prenant la moyenne du temps entre le premier et le dernier étudiant. La durée de l'application du test fut 150 minutes.

\subsubsection{Fidélité du test :}

Pour calculer la fidélité du test, nous avons fait deux passations au début d'octobre 2016, puis deux semaines après. Nous avons calculé la corrélation entre les deux passations en suivant la formule statistique de spirman (El-Bahy, 1997)

Indice de fidélité $=\underline{2 \mathrm{R}}$ 
مجلة كلية التربية بالإسماعيلية - العدد الثامن والثلاثون - مايو PV r P $1+\mathrm{R}$

Donc, la fidélité du test était 0,74

\section{$\underline{\text { 2.1.4.4 validité du test : }}$}

Nous avons présenté le test aux membres du jury pour voir si le test est convenable au niveau d'étudiants de la quatrième à la section du Français dans la faculté de pédagogie de Damiette.

Le chercheur a pris en considération toutes les remarques proposées par les membres du jury.

Aussi, on a calculé la validité du test à partir de sa fidélité en appliquant la formule suivante (El-Bahy, 1979).

\subsubsection{5 notations du test :}

Nous avons consacré 100 notes à la note totale du test. Ces notes sont distribuées aux cinq questions (20 notes pour chaque question).

\subsection{Elaboration du programme proposé:}

Afin de préparer le programme proposé pour améliorer les compétences de la traduction d'étudiants de la quatrième année à la section du Français dans la faculté de pédagogie de Damiette, nous avons entrepris les étapes suivantes :

\subsubsection{Délimiter les objectifs du programme proposé.}

2.2.2 Déterminer les sources des histoires numériques.

2.2.3 Elaborer le contenu des histoires numériques.

$\underline{\text { 2.2.1 les objectifs du programme proposé }}$ 
Notre programme proposé basé sur l'approche pragmatique à la lueur de la communication interculturelle a pour but de développer les compétences de la traduction chez les futurs enseignants du Français à la Faculté de pédagogie. Ces compétences comportent les suivants:

- Saisir la langue de départ et la langue d'arrivée.

- Maîtriser exactement des terminologies et des concepts dans la langue de traduction.

- Choisir le style convenable pour les nouveaux concepts.

- Comprendre des sujets complexes et élaborer le sens des textes obscurs.

- Détecter les contradictions des incohérences, le non-sens et les erreurs logiques, ou les faits.

- Avoir une bagage linguistique étendu dans la langue cible.

- Connaitre les aspect culturelles de texte cible.

- Mettre en considération les aspects sociolinguistique et pragmatiques pendant la traduction.

\section{$\underline{\text { 2.2.2 Déterminer les sources du programme proposé }}$}

Pour préparer le programme proposé, le chercheur a eu recours aux sources suivantes :

Abaplanalp, L.(2002). Vers une théorie sémantico-pragmatique pour la traduction, Göppingen, Kummer Vertag.

Levinson, S. (1983). Pragmatics, Cambridge, CUP.

Olivier, M.( 2004). Management interculturel, Paris, Editions Dunod,

PEIRCE, Ch. (2002). Euvres philosophiques, Pragmatisme et pragmaticisme, Paris, Ed. du Cerf.

Triki, M.(2013). " A Pragmatic Approach to the Study of English / Arabic Translation Errors", Journal Academica, Vol. 3(1), pp. 39-51. 


\section{$\underline{\text { 2.2.3 Elaborer le contenu du programme proposé }}$}

On a élaboré cinq unités visant à améliorer les compétences de la traduction d'étudiants de la quatrième année à la section du Français dans la faculté de pédagogie de Damiette.

\subsection{Enseignement des programme proposé :}

Après avoir appliqué le pré-test, on a enseigné le programme en quatrième semestre de l'année universitaire 2016 - 2017 à partir14 novembre jusqu'à 21 décembre. On a enseigné le programme proposé basé sur l'approche pragmatique à la lueur de la communication interculturelle aux étudiants de la quatrième année à la section du Français dans la faculté de pédagogie de Damiette comme un groupe expérimental.

Cette application a duré 5 semaines à moyenne deux rencontres par semaine (à raison de 90 minutes pour chaque rencontre).

\subsection{Application du Post - Test :}

A la fin de l'enseignement de notre programme basé sur l'approche pragmatique à la lueur de la communication interculturelle, nous avons réappliqué le même test de la traduction post test 22 décembre 2016 aux sujets de notre groupe expérimental afin de détecter le degré d'amélioration des futurs enseignants du français aux compétences de la traduction. Ainsi, nous passons à l'analyse statistique des résultats.

\section{$\underline{2.5}$ Analyse des résultats :}

Pour analyser les résultats du pré-post test de traduction ,le chercheur a utilisé le test de (T) selon le programme SPSS 
effectué sur l'ordinateur. A cet égard ,la valeur de "T" est calculée au niveau du pré-post test dans son ensemble.

\section{Tableau No.1}

\section{Les résultats relatifs au pré- post de la traduction}

\begin{tabular}{|c|c|c|c|c|c|c|}
\hline Test & $\mathrm{N}$ & $\begin{array}{c}\text { Moyenne } \\
\text { Arithmétique }\end{array}$ & $\begin{array}{c}\text { Écart } \\
\text { type }\end{array}$ & $\begin{array}{c}\text { Dégré } \\
\text { de } \\
\text { liberté }\end{array}$ & $\begin{array}{c}\text { Valeur } \\
\text { de T }\end{array}$ & $\begin{array}{c}\text { Niveau de } \\
\text { signification }\end{array}$ \\
\hline $\begin{array}{c}\text { Pré- } \\
\text { test }\end{array}$ & 35 & 71.57 & 16.86 & 35 & 15.496 & 0.000 \\
\hline $\begin{array}{c}\text { Post- } \\
\text { test }\end{array}$ & 35 & 104.51 & 18.977 & 35 & 15.496 & 0.000 \\
\hline
\end{tabular}

Le tableau précédent montre qu'il existe une différence significative entre la moyenne des notes " $M$ " des étudiants en ce qui concerne le pré-post test du groupe expérimental au niveau de 0.000 en faveur du post-test, aussi la valeur de " $T$ " qui est significative au niveau de 0.000 .Ce qui démontre le développement des compétences de traduction chez l'échantillon de la recherche.

Nous remarquons qu'il y a une différence statistiquement significative entre les moyennes des notes du groupe expérimental au pré et post-test des performances de la production écrite en faveur du post-test.

La valeur de "T" calculé (15.496) est plus grande que celle du tableau (2.39) au niveau de $p>01$. Ce qui met en valeur la progression dû à l'utilisation de notre programme proposé basé sur l'approche pragmatique à la lueur de la communication interculturelle :

- L'approche pragmatique ont amélioré les compétences de la traduction chez les futurs enseignants du Français grâce à 
l'adaptation pragmatique qui est la relation étroite entre la culture et la langue.

- L'approche pragmatique à la lueur de la communication interculturelle favorise la compétence de transfert qui joue un rôle actif dans la traduction des textes dans la langue cible. Sans compétence de transfert, les traducteurs ne parviennent pas à effectuer le rendu dans la langue cible.

- L'approche pragmatique permet de communiquer efficacement en impliquant à la fois des compétences grammaticales et des connaissance pragmatiques; elle comporte sociolinguistique qui nous permet pour exécuter des fonctions linguistiques de manière appropriée à ce contexte

- les adaptations pragmatiques sont considérées comme des solutions aux problèmes de traduction qui concernent les facteurs situationnels.

\subsection{Calcul de l'efficacité du programme :}

Afin d'évaluer l'efficacité de notre programme ,on a d'abord calculé "la taille d'effet " du programme proposé. En effet ,'indice 'Eta- Carré "permet d'apprécier l'importance de l'effet de la variable indépendante sur la variable dépendante. l'efficacité du programme se confirme quand la taille d'effet est grande.

La taille d'effet se calcule par la formule suivante :Eta Carré $=[($ somme des carrés de l'effet $) /($ somme des carrés de l'effet )+(les degrés de liberté)] Pour cette équation de Cohen 1988 : Quand Eta Carré $\leq 0.01$ "l'effet soit de petite taille Quand Eta Carré $\leq 0.06$ "l'effet soit de taille moyenne ; Quand Eta Carré $\geq 0.014$ "l'effet soit de grande taille. 


\section{Tableau No.1 : l'efficacité du programme}

\begin{tabular}{|c|c|c|c|c|c|}
\hline & T2 & DL & $\begin{array}{c}\text { Eta } \\
\text { carré }\end{array}$ & $\begin{array}{c}\text { Valeur } \\
\text { d'efficacité }\end{array}$ & $\begin{array}{c}\text { Type de taille } \\
\text { d'effet }\end{array}$ \\
\hline $\begin{array}{c}\text { Pré- } \\
\text { post test }\end{array}$ & 240.126 & 34 & 0.875 & 5,1 & Grande \\
\hline
\end{tabular}

La valeur de signification s'est calculée par la formule suivante $V=2 \sqrt{\frac{\text { eta carré }}{\text { (1-eta carré) }}}$

Pour cette équation de (Réda Mossad 2011) :

Quand la valeur d'efficacité $\leq 0.2$ "l'effet soit de petite taille

Quand la valeur d'efficacité $\leq 0.5$ "l'effet soit de taille moyenne

Quand la valeur d'efficacité $\geq 0 . .8$ "l'effet soit de grande taille

D'après ce tableau ,nous remarquons l'efficacité du programme basé sur l'approche pragmatique à la lueur de la communication interculturelle pour développer les compétences de traduction chez les futurs enseignants à la faculté de pédagogie .Les résultats indiquent qu'il y a une amélioration au niveau des compétences de traduction chez le groupe expérimental avec une grande taille d'effet remarquable .Ce développement est dû à l'efficacité de notre programme.

\subsection{Recommandations de la recherche :}

A la lueur des résultats de la recherche, nous pourrions recommander de $\left(\mathrm{d}^{\prime}\right)$ :

- Présenter les activités de traduction dans la salle de classe qui peuvent mettre en pratique les quatre compétences et les quatre systèmes. En ce qui concerne la compétence 
communicative, ils nécessitent une précision, la clarté et la flexibilité.

- se concentrer sur des objectifs spécifiques d'apprentissage des activités de traduction comme la pratique de certains vocabulaires, des points de grammaire, des styles et des registres; et aussi d'autres outils tels que le courrier électronique et les pages Web de classe.

- S'intéresser à l'entraînement de la traduction en groupes pour encourager les apprenants à discuter la signification et l'utilisation de la langue au niveau le plus profond possible dans leur travail à travers le processus de compréhension et la recherche d'équivalents dans une autre langue.

- Discuter les différences et les similitudes au cours du processus de traduction pour aider les apprenants à comprendre l'interaction de deux langues et les problèmes causés par leur L1; à apprécient les points forts et les points faibles de la L1 et L2, par exemple dans la comparaison des idiomes telles que les métaphores.

- Prêter une grande attention aux différences stylistes et naturelles dans les cultures sources et cibles lors du transfert d'un texte d'une culture à l'autre. L'une des principales caractéristiques de la traduction est la « situation de double lien », où le traducteur doit lier le texte source dans son contexte culturel à la condition de communication culturelle cible.

- $\quad$ souligner que le processus de transcodage devrait être axé non seulement sur Le transfert de langue, mais aussi - et surtout - sur la transposition culturelle car les traducteurs doivent être bilingues et biculturels, sinon multiculturels

- Attirer l'attention des conseillers et des superviseurs pédagogiques à inviter leurs stagiaires à employer 
l'approche pragmatiques afin de développer leurs différentes compétences langagières en Français.

\subsection{Suggestions de la recherche}

A partir des résultats obtenus par notre étude, le chercheur suggère les thèmes suivants en langue française :

- Enquêter le rôle de l'approche pragmatique pour développer les compétences productives ( élocution, écriture ) chez les futurs enseignants aux Facultés de Pédagogie.

- Elaborer un programme proposé basé sur l'approche pragmatique pour améliorer les compétences du discours critique en Français chez les futurs enseiganants à la faculté de Pédagogie.

- Vérifier l'efficacité de l'approche pragmatique pour developper les competences de la compréhension écrite chez les élèves du cycle préparatoire et du cycle secondaire.

- Elaborer des programmes visant à fonctionner l'approche pragmatique au processus de l'enseignement chez les professeurs de la langue française en service.

- Effectuer un nombre d'études pour développer les compétences de la traduction dans tous les cycles scolaires et les niveaux langagières.

- Proposer des programmes en vue de développer les compétences de la traduction chez les enseignants du Français.

- Evaluer les méthodes d'enseignement suivies aux facultés de Pédagogie à la lueur de l'approche pragmatique et l'adaptation pragmatique dans les langues étrangères. 


\section{BIBLIOGRAPHIE}

Abaplanalp, L.(2002). Vers une théorie sémantico-pragmatique pour la traduction, Göppingen, Kummer Vertag.

Abbasi ,G; zadeh, S ; Assemi.A .\& Dehghan,S.(2012). Language, Translation, and Culture, Singapore, IACSIT Press.

Aguado, P. \& Perez, P.(2005). "Translation-strategies use : a classroom-based examination of Baker's taxonomy ". Meta, vol. 50, no. 1, p. 294-311.

Baker, M. \& Saldanha, G.(2011). Routledge Encyclopedia of Translation Studies, New York.

Ballard, M. (2009). Traductologie et enseignement de la traduction à l'université, études réunies ,Traductologie, Artois, Presses Université.

Barekat, B.(2013 ). Investigating the Effect of Metalinguistic Feedback in L2 Pragmatic Instruction, International Journal of Linguistics ISSN, Vol. 5, No. 2.

Caws, C. (2009). " Contexte et culture en enseignement du FLS : de la création d'un corpus a son exploitation didactique ". Mélanges Crapel, N.31, Université de Nancy.

Chaplier , C.(2012). "Communication Interculturelle Exemples de rhétorique et de pragmatique culturelles". Education, Socioculturel, N.35, PP.147-169.

Chesterman, A.(2009). " The Name and Nature of Translator Studies ". Journal of Language and Communication Studies, University of Helsinki, no.42.

Chesterman, A. \& Wagner, E.(2014). " Universalism in translation studies". Translation studies, Vol.7, N.1, PP. $82-90$.

Coban, A(2015). "Analysis and training of the required abilities and skills in translation in the light of translation models and general theories of translation studies". 
7th World Conference on Educational Sciences, (WCES), Novotel Athens Convention Center, Athens, Greece, Procedia - . Social and Behavioral Sciences, February, pp. $707-714$

Commission européenne - Direction générale de la traduction.( 2010). "Etude Portant sur la contribution de la traduction à la société multilingue dans l'Union européenne Union".

Crevier, V.(2002). " L'interdisciplinarité en travail : Du projet intellectuel aux pratiques de l'ordre de l'excellence" in Gélineau, L'interdisciplinarité et la recherche sociale appliquée, Canada, Université de Montréal.

Demetska ,V(2011). " TRANSLATIONAL ADAPTATION: THEORETICAL AND METHODOLOGICAL PERSPECTIVES". Advanced Science Journal, VOL.11, pp 15-18.

Du, V. (2016 ). " The Adaptation Approach to College Foreign Language Teaching, 2nd International Conference on Education Technology". Management and Humanities Science, Atlantis Press.

Elfoul , L. (2006). Traductologie, littérature comparée, études et essais, Alger, Casbah éditions.

Farah, S. (2015). " La traduction dans l'enseignement / apprentissage du FLE". Thèse de Magistère, Faculté des lettres et des langues, Université de Tlemcen.

Fath , N.(2009). " Déficit culturel et inaptitude interprétative en classe FLE : une approche cognitive". Synergies Pays Scandinaves , N.4, pp. 43-55.

Gile, D.(2005). La traduction. La comprendre, l'apprendre, Paris, Presses universitaires de France.

Gisèle, S.(2008). Situation du français sur le marché mondial de la traduction Translatio: Le marché de la traduction en France à l'heure de la mondialisation, Paris, CNRS Éditions. 
مجلة كلية التربية بالإسماعيلية - العدد الثامن والثثلاثون - مايو IV P P

Glodjović, A.(2010). "Translation As A Means of Cross-Cultural Communication: Some Problems in Literary Text Translations ". Linguistics and Literature, Vol. 8, No.2, , pp. $141-151$.

Guidere , M. (2010). La traduction à la trauductologie , paris, DeBoek.

Gutt, E. A. (,1991). Translation and Relevance, Oxford, Basil Blackwell.

Gutu, A.(2012). La communication interculturelle à travers la traduction : le cas de la pyramide segmentée, LA FRANCOPOLYPHONIE, Vol. 2, PP. 11-16.

Kambaja, E.(2009). " Approche pragmatique et son application au processus de la traduction français ".Thèse de doctorat, Université de Lubumbashi.

Kitis , E.((2009). " Pragmatic infrastructure in translation". Traduction et Communication, N.18.

Koivisto, A. 2006. Pragmatic adaptation in translating belleslettres with special reference to Niccolò Ammaniti's Io non ho paura and its Finnish and German translations]. MA thesis. School of Languages and Translation Studies, University of Turku.

Kosonen , P.(2011). " PRAGMATIC ADAPTATION IN TRANSLATING SKEPTICS VS CREATIONISTS: A FORMAL DEBATE FROM ENGLISH INTO FINNISH ". Master's thesis, University of Jyväskylä.

Kulczycka, K.\& Woln, O.(2014). " Théories, approches et modèles de la traduction". Journal de linguistique appliquée, vol.59.

Lafeber, A.(2012 ). " Translation Skills and Knowledge Preliminary Findings of a Survey of Translators and Revisers Working at Inter-governmental Organizations" . la promotion de l'employabilité et de la recherche, Volume 57, numéro1, Mars. 
Lavault, E.(1985). Fonctions de la traduction en didactique des langues, Paris, Didier Erudition.

Lederer, M.\& SELESKOVITCH, D.(2001). Interpréter pour traduire, Quatrième édition revue et corrigée, Paris, Didier Erudition.

Levinson, S. (1983). Pragmatics, Cambridge, CUP.

Licata,L \& Heine, A.(2012). Introduction à la psychologie interculturelle, Paris, De Boeck.

Lindenberg, J. \& Vegliante, Ch.(2011). La répétition à l'épreuve de la traduction, Paris, Bouquiné d'ISBN.

Marzouk, I.( 2013). " LE RECOURS À LA TRADUCTION ET SON RÔLE DANS L'ENSEIGNEMENT/APPRENTISSAGE DU FRANÇAIS LANGUE ÉTRANGÈRE À BAHREÏN". Thèse de Doctorat, UNIVERSITÉ PAUL VALÉRY, MONTPELLIER III.

Meier, O.( 2004). Management interculturel, Paris, Editions Dunod,

Musampa, E.K.(2011). "L'environnement cognitif du traducteur et l'interdisciplinarité dans la pratique de la traduction". Synergies Roumanie, $\mathrm{n}^{\circ}$ 6, pp. 29-40.

Natunen, T.( 2003). " Pragmatic adaptation in translating belleslettres with special reference to the German translation ". MA thesis. School of Modern Languages and Translation Studies, University of Tampere.

Nord, Ch.(2005). Text Analysis in translation : theory, methodology and didactic Application of a model for translation - oriented text analysis, second edition, New York, Ny.

Omar, H . \& Mohamed, N.Z .(2014). " TESL Undergraduate Student Teachers' View on Translation in a Rural School ". Journal of Teaching and Teacher Education, No. 1, PP.61-68. 
Peirce, Ch. (2002). Euvres philosophiques, Pragmatisme et pragmaticisme, Paris, Ed. du Cerf.

Pettinen, A.(1998). " Pragmatic adaptation in the puppet show Laiska Ivan". Master's thesis, Department of Modern Languages, University of Helsinki.

Real, E. ; Jiménez, D.; Pujante, D. \& Cortijo, A.(2001). Écrire, traduire et représenter la fête, Université de Valencia, I.S.B.N.

Ruschiensky , C.(2015 ). " Competence and Creativity in Translation: Multilingual Perspectives". Master theisis , Concordia University Montreal, Quebec, Canada.

Samara, R.(2003). " La poésie d'une traduction à l'autre" In Mejri, S. (sous dir.), Traduire la langue, traduire la culture, Paris / Tunis, Maisonneuve et Larose / Sud Edition, PP.305 - 326.

Sawant, D .(2010). " TRANSLATION: AN EFFECTIVE WAY TO CROSS-CULTURAL COMMUNICATION IN GLOBALIZATION". Available from https :// Www .researchgate .net/publication/215485822 Translation An Effecti ve Way To Cross- cultural Communication in Globalization).

Shan, Bo .(2004) "La communication interculturelle, ses fondements, les obstacles à son développement Communication et organisation ". Meaning in translation, peter lang.

Sperber,D. \& WILSON D. (2003). " Concepts. Philosophy of Language/Issues in Pragmatics Lectures". Linguistic journal, University College London.

Svenbro, A. (2009), "Quel espace pour la traduction en bibliothèque ?". Mémoire pour le Diplôme de conservateur de bibliothèque, ENSSIB, numéro 7, mai. 
Tatilon, C. (1986). Traduire. Pour une pédagogie de la traduction, collection « Traduire, écrire, lire », Paris, GREF.

Triki, M.(2013). " A Pragmatic Approach to the Study of English / Arabic Translation Errors", Journal Academica, Vol. 3(1), pp. 39-51.

Tsatourova, I.A. \& Kashirina, N.A. (2008). Analyse traductologique du texte, langue anglaise. Manuel avec le support didactique, Saint-Petersbourg, Perspektiva.

Totschnig, M. (2000). " Eléments pour une théorie pragmatique de la communication ". disponible de http : // www.er.uqam.ca/ nobel/d364101 pragmatique.shtml.

Vandyk, J. (2007). " L'intérêt de l'enseignement de la traduction à vue à des apprenants de FLE". Thèse de majestère, Faculté des sciences humaines, Université de Pretoria.

Vehmas, I. (2002). " Kopiointia vai kommunikointia? Johdatus käännösteoriaan

[Copying or communication? An introduction to translation theory] ". Helsinki: Oy Finn Lectura Ab.

Verschueren, J. (2000). Handbook of Pragmatics online, Amsterdam, John Benjamins.

Volkova, T., \& Zubenina, M.(2015). " Pragmatic and Sociocultural Adaptation in Translation: Discourse and Communication Approach". SKASE JOURNAL OF TRANSLATION AND INTERPRETATION, VOL. 8 No. 1, pp.89 -106.

Yule, G. (1996). Pragmatics, Oxford, CUP.

Zaghouani - Dhaouadi, H. (2008). " Essai de Didactologie des

Langues-Cultures. Pour une nouvelle conception de l'enseignement-apprentissage des langues-cultures ". Synergies Espagne, N. 1, PP. 75-88. 


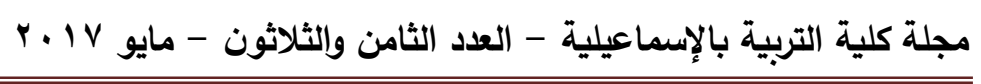

Zhang, Ch. (2014)." Translators' Subjectivity on the Lexical Level under the Pragmatic Adaptation Theory- A Case Study of the English Version of Fortress Besieged". Theory and Practice in Language Studies, Vol. 4, No. 1, pp. 155-159.

Zixia , ch.(2009). " A Cognitive-Pragmatic Model for Translation Studies Based on Relevance and Adaptation Canadian ". Social Science, Vol.5, No.1, February, PP.88-111.

رضا مسعد السعيد. (11 + (1). الإحصاء النفسي و التربوي (نماذج و أساليب حديثة)، الاسكندرية، مكتبة الكتاب الجامعي.

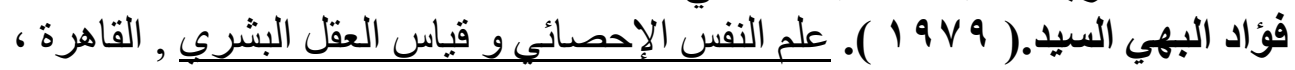
دار الفكر الكربي. 